\title{
Bortezomib-induced thrombotic thrombocytopaenic purpura
}

\author{
Neha Mehta, Ashish Saxena, Ruben Niesvizky \\ Department of Medicine, New York Presbyterian-Weill Cornell Medical Center, New York, New York, USA \\ Correspondence to Dr Ruben Niesvizky, run9001@med.cornell.edu
}

\begin{abstract}
Summary
Thrombotic thrombocytopaenic purpura (TTP) is a thrombotic microangiopathy characterised by haemolytic anaemia, schistocytes on peripheral blood smear and thrombocytopaenia that can additionally present with fever, renal insufficiency and/or neurological abnormalities. While our understanding of idiopathic TTP has significantly advanced, there are still many unanswered questions regarding the pathophysiology of secondary TTP, which can be associated with malignancy, pregnancy, HIV infection, bone marrow transplantation and exposure to certain drugs including several chemotherapeutic agents. Here we present a case of bortezomib-associated TTP. Our patient developed microangiopathic haemolytic anaemia, thrombocytopaenia and altered mental status after her ninth dose of bortezomib. The drug was subsequently discontinued and the patient underwent one session of plasma exchange with clinical improvement and recovery of her platelet counts, disappearance of schistocytes and resolution of both neurological symptoms and haemolysis in 2 days.
\end{abstract}

\section{BACKGROUND}

Thrombotic thrombocytopaenic purpura (TTP) is a thrombotic microangiopathy resulting in red blood cell haemolysis and thrombocytopaenia. The 'classic pentad' of features in TTP also includes fevers, renal insufficiency and neurological alteration. However, it is rare for all five of these components to be present in a particular patient and only microangiopathic haemolytic anaemia and thrombocytopaenia are required to suspect the diagnosis. Deficiency of ADAMTS13 activity, a metalloprotease that cleaves large multimers of von Willebrand factor, as well as the presence of antibodies against this enzyme have both been associated with idiopathic TTP. However, the mechanisms of secondary TTP are yet to be fully elucidated. Secondary TTP has been associated with malignancy, bone marrow transplantation, pregnancy and HIV infection, as well as with exposure to certain drugs. There have been a number of hypotheses regarding the causes of drug-associated TTP. ${ }^{1}$ Some speculate that these drugs cause direct endothelial damage. Some drugs, such as quinine, have been associated with antibody proliferation, which react with platelet-glycoprotein complexes to cause a thrombotic microangiopathy. ${ }^{2}$ Many chemotherapeutic agents have been associated with secondary TTP, including gemcitabine, cisplatin, mitomycin-C, bleomycin, pentostatin and docetaxel. Bortezomib is a proteosome inhibitor indicated in the treatment of multiple myeloma and mantle cell lymphoma. The development of TTP following treatment with this drug is very uncommon. Here we present a case of bortezomib-associated TTP reported in the literature.

\section{CASE PRESENTATION}

A 70-year-old woman with a history of hypertension and a recent diagnosis of IgA lambda multiple myeloma presented to our tertiary-care hospital in New York City with lethargy and confusion. The patient was diagnosed with ISS Stage 3, IgA lambda multiple myeloma 1 month prior to this admission when she presented to a different hospital with lethargy and was found to have an IgA level in the $6000 \mathrm{mg} / \mathrm{dl}$ range and a bone marrow biopsy showing $94 \%$ plasma cells with a monoclonal lambda population. At that time she was transferred to our hospital where she was found to have a serum protein of $11 \mathrm{~g} /$ $\mathrm{dl}$ and serum viscosity of $6.7 \mathrm{cSt}$. She underwent three sessions of plasmapheresis to treat hyperviscosity syndrome and was started on treatment for multiple myeloma with the CyBorD chemotherapy regimen (cyclophosphamide $300 \mathrm{mg} / \mathrm{m}^{2}$ intravenous on days 1 and 8 and bortezomib $1.3 \mathrm{mg} / \mathrm{m}^{2}$ intravenous with $40 \mathrm{mg}$ dexamethasone orally on days 1, 4, 8 and 11 of a 21 -day cycle). ${ }^{3}$ There was subsequent improvement in her serum viscosity to $2.5 \mathrm{cSt}$ and her serum IgA fell to $2100 \mathrm{mg} / \mathrm{dl}$. The patient was discharged and completed cycle 1 of CyBorD as an outpatient.

Six days after discharge, however, the patient's family noted that she was confused and lethargic and returned her to the emergency department. At that time she was found to have a creatinine of $8.5 \mathrm{mg} / \mathrm{dl}$ from a baseline of $0.4 \mathrm{mg} /$ $\mathrm{dl}$ and was admitted to the medical intensive care unit. Her presentation was thought to be most consistent with acute tubular necrosis in the setting of dehydration from poor PO intake and diarrhoea. As she was anuric with a uric acid of $13.7 \mathrm{mg} / \mathrm{dl}$ and phosphorus of $10.4 \mathrm{mg} / \mathrm{dl}$, the decision was made to pursue emergent haemodialysis. The patient remained dialysis-dependent for the duration of her hospitalisation. On day 16 of her hospitalisation, the patient began cycle 2 of CyBorD, which she completed without incident. She began cycle 3 of this regimen on hospital day 37 , receiving her ninth dose of bortezomib on that day. On the night of hospital day 39, 2 days after her last dose of bortezomib, the patient complained of diffuse weakness and pigmenturia that was maroon-to-black in colour. By the following day her haemoglobin level had decreased from 9.5 to $7.0 \mathrm{~g} / \mathrm{dl}$. During this same period,the patient's platelet count dropped from $188000 / \mu$ to $105000 / \mu 1$. Further chemotherapy was held. The next morning the patient demonstrated mood lability and complained of worsening diffuse weakness. 


\section{INVESTIGATIONS}

Given her pigmenturia, a urinalysis was performed which demonstrated large blood but only 4-10 red blood cells per high-power field as well as large urine bilirubin but urobilinogen of $1.0 \mathrm{EU} / \mathrm{dl}$. Urine culture grew out vancomycin-resistant enterococcus but blood cultures were negative and no fevers were recorded. Further blood work demonstrated lactate dehydrogenase of 1565 IU/1 (increased from $236 \mathrm{IU} / 15$ days prior) as well as a haptoglobin of $<15 \mathrm{mg} / \mathrm{dl}$ and a total bilirubin level of $1.3 \mathrm{mg} / \mathrm{dl}$ with an indirect portion of $1.0 \mathrm{mg} / \mathrm{dl}$. Peripheral blood smear was reviewed and demonstrated two schistocytes per high-power field without microspherocytes (figure 1). All these findings suggested microangiopathic haemolysis. As disseminated intravascular coagulation (DIC) was on the differential diagnosis, fibrinogen level was found to be normal at $244 \mathrm{mg} / \mathrm{dl}$ and international normalized ratio was normal at 1.0 with an aPTT of 24.4, weakening the case for DIC. An ADAMTS13 activity level was sent.

\section{TREATMENT}

The patient's case was concerning for intravascular haemolysis from TTP. She was initially given one unit of packed red blood cells with transient improvement in her haemoglobin from 7.0 to $8.7 \mathrm{~g} / \mathrm{dl}$, but this decreased again to $8.0 \mathrm{~g} / \mathrm{dl}$ within $5 \mathrm{~h}$. The decision was made to hold further chemotherapy with bortezomib. Additionally, the patient underwent one session of plasma exchange on hospital day 41 .

\section{OUTCOME AND FOLLOW-UP}

On hospital day 42 the patient's lactate dehydrogenase (LDH) began to decrease and her haptoglobin level began to rise; by hospital day 44 her LDH was $385 \mathrm{IU} / 1$ and her haptoglobin was $134 \mathrm{mg} / \mathrm{dl}$. Her indirect hyperbilirubinaemia resolved within 2 days as well. The patient's haemoglobin remained between 7 and $8 \mathrm{~g} / \mathrm{dl}$ until hospital day 47 when she responded appropriately to packed red blood cell transfusion and maintained a haemoglobin level at her original baseline of 9-10 g/dl. Her platelet count also began rising slowly starting on hospital day 42 and normalised to $154000 / \mu 1$ on hospital day 47.

ADAMTS13 activity level drawn prior to plasmapheresis resulted at $31 \%$, with lower limit of normal being

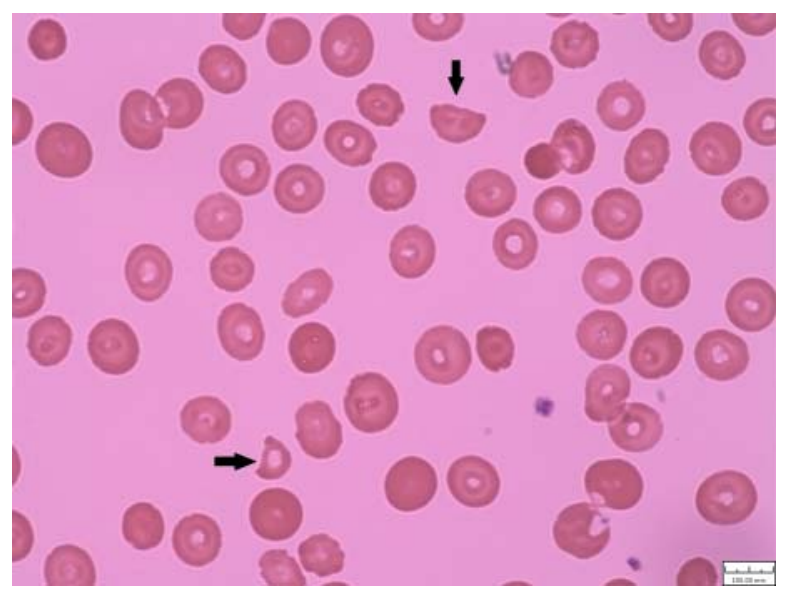

Figure 1 Peripheral smear on hospital day 40 demonstrating schistocytes as marked by arrows.
67\%. A repeat ADAMTS13 level obtained 4 weeks afterwards was found to be $100 \%$. Bortezomib chemotherapy was not restarted and the patient was later placed on maintenance treatment with lenalidomide for her multiple myeloma.

\section{DISCUSSION}

This patient represents the third case of TTP associated with bortezomib, which has been reported in the literature. Both prior cases were seen in patients after their first dose of bortezomib. ${ }^{4}{ }^{5}$ The first reported case occurred 8 days after introduction of bortezomib and the second occurred 2 days after the introduction of bortezomib. This case occurred 2 days after our patient's ninth dose of bortezomib. Therefore, this is the first case reported in which a thrombotic microangiopathy did not occur with the initial dose of bortezomib but occurred shortly after a subsequent dose. It is unclear as to why the patient was able to receive several doses of the drug prior to the development of TTP. It is possible that her particular clinical circumstances, including relatively new renal failure and urinary tract infection with enterococus, somehow played a role. Additionally, it has been hypothesised that TTP after bortezomib is associated with IL-6-mediated microangiopathy and a high burden of disease. ${ }^{5}$ However, in this case, at the onset of TTP, the patient's burden of disease had improved and was relatively low compared to what it was at prior exposures to bortezomib. In both prior cases, ADAMTS13 activity was also diminished at $12 \%$ and $36 \%$, but in one case the ADAMTS13 activity remained low when bortezomib was reintroduced and the patient did not have recurrence of TTP. ${ }^{5}$ This supports prior literature which suggests that the presence of drug-induced TTP does not correlate with ADAMTS13 activity or antibody levels. ${ }^{6}$

The role of plasma exchange in drug-induced TTP has been controversial. In prior studies of secondary TTP, plasma exchange was found to have variable outcomes. ${ }^{67}$ Therefore drug-induced TTP is often treated by holding the offending agent. $^{8}$ In the first described case of bortezomib-induced TTP, the patient was treated with fresh frozen plasma and haptoglobin. ${ }^{4}$ In the second case, TTP resolved as bortezomib was withheld. ${ }^{5}$ Plasma exchange has been associated with improving renal function in cyclophosphamide-induced microangiopathic haemolytic anaemia and associated with decreased mortality in clopidogrel-induced TTP. ${ }^{10}$

\section{Learning points}

- Thrombotic thrombocytopaenic purpura has been associated with multiple chemotherapeutic and immunomodulatory agents including gemcitabine, mitomycin C, cisplatin, docetaxel, bleomycin and bortezomib.

- ADAMTS13 activity level or antibody testing is not critical to making the diagnosis of drug-induced TTP.

- Treatment of drug-induced TTP should always involve removing the offending agent. The role of plasma exchange in these cases is controversial and may be helpful in certain cases of drug-induced TTP. 


\section{BMJ Case Reports}

Competing interests $\mathrm{Dr}$ Ruben Niesvizky would like to disclose that he is involved in research supported by Onyx, Celgene and Millennium. He is a speaker for Celgene and Millennium and Consultant for Celgene, Millennium and Onyx. Dr Saxena and Dr Mehta do not have anything to disclose.

Patient consent Obtained.

\section{REFERENCES}

1. Zakarija A, Bennett C. Drug-Induced thrombotic microangiopathy. Semin Thromb Hemost 2005:31:681-90.

2. Gottshall JL, Neahring B, McFarland JG, et al. Quinine-induced immune thrombocytopenia with hemolytic uremic syndrome: clinical and serological findings in nine patients and review of literature. Am J Hematol 1994;47:283-9.

3. Reeder CB, Reece DE, Kukreti V, et al. Cyclophosphamide, bortezomib and dexamethasone induction for newly diagnosed multiple myeloma: high response rates in a phase II clinical trial. Leukemia 2009;23:1337-41.

4. Morita R, Hashino S, Shirai S, et al. Thrombotic microangiopathy after treatment with bortezomib and dexamethasone in a patient with multiple myeloma. Int J Hematol 2008;88:248-50.
5. Moore H, Romeril K. Multiple myeloma presenting with a fever of unknown origin and development of thrombotic thrombocytopenic purpura post-bortezomib. J Int Med 2011:41:348-50.

6. Zheng XL, Kaufman RM, Goodnough LT, et al. Effect of plasma exchange on ADAMTS13 metalloprotease activity, inhibitor level, and clinical outcome in patients with idiopathic and nonidiopathic thrombotic thrombocytopenic purpura. Blood 2004;103:4043-9.

7. Lesesne JB, Rothschild N, Erickson B, et al. Cancer associated hemolytic-uremic syndrome: analysis of 85 cases from a national registry. J Clin Oncol 1989;7:781-9.

8. George J. How I treat patients with thrombotic thrombocytopenic purpura-hemolytic uremic syndrome. Blood 2000;96:1223-9.

9. Pham PT, Peng A, Wilkinson AH, et al. Cyclosporine and tacrolimus associated thrombotic microangiopathy. Am J Kidney Dis 2000;36: 844-50.

10. Zakarija A, Bandarenko N, Pandey DK, et al. Clopidogrel-associated TTP: an update of pharmacovigalance efforts conducted by independent researchers, pharmaceutical suppliers and the Food and Drug Administration. Stroke 2004;35:533-7.

This pdf has been created automatically from the final edited text and images.

Copyright 2012 BMJ Publishing Group. All rights reserved. For permission to reuse any of this content visit http://group.bmj.com/group/rights-licensing/permissions.

BMJ Case Report Fellows may re-use this article for personal use and teaching without any further permission

Please cite this article as follows (you will need to access the article online to obtain the date of publication).

Mehta N, Saxena A, Niesvizky R. Bortezomib-induced thrombotic thrombocytopaenic purpura. BMJ Case Reports 2012;10.1136/bcr-2012-006461, Published XXX

Become a Fellow of BMJ Case Reports today and you can:

- Submit as many cases as you like

- Enjoy fast sympathetic peer review and rapid publication of accepted articles

- Access all the published articles

- Re-use any of the published material for personal use and teaching without further permission

For information on Institutional Fellowships contact consortiasales@bmjgroup.com

Visit casereports.bmj.com for more articles like this and to become a Fellow 